Portland State University

PDXScholar

Engineering and Technology Management

Faculty Publications and Presentations

\title{
Selecting Medical Hardware using Pairwise \\ Comparisons: A Patient's Perspective of Cochlear Implant Device Selection
}

Timothy R. Anderson

Portland State University, tim.anderson@pdx.edu

Shabnam Razeghian Jahromi

Jama Software

Follow this and additional works at: https://pdxscholar.library.pdx.edu/etm_fac

Part of the Biomedical Engineering and Bioengineering Commons, and the Medical Biotechnology Commons

Let us know how access to this document benefits you.

\section{Citation Details}

Anderson, Timothy R. and Jahromi, Shabnam Razeghian, "Selecting Medical Hardware using Pairwise Comparisons: A Patient's Perspective of Cochlear Implant Device Selection" (2016). Engineering and Technology Management Faculty Publications and Presentations. 93.

https://pdxscholar.library.pdx.edu/etm_fac/93

This Article is brought to you for free and open access. It has been accepted for inclusion in Engineering and Technology Management Faculty Publications and Presentations by an authorized administrator of PDXScholar. Please contact us if we can make this document more accessible: pdxscholar@pdx.edu. 


\title{
Selecting Medical Hardware using Pairwise Comparisons: A Patient's Perspective of Cochlear Implant Device Selection
}

\author{
Timothy R. Anderson ${ }^{1}$, Shabnam R. Jahromi ${ }^{2}$ \\ ${ }^{1}$ Dept. of Engineering and Technology Management, Portland State University, Portland, OR - USA \\ ${ }^{2}$ Jama Software, USA
}

\begin{abstract}
Selecting medical hardware can be a difficult and permanent decision for patients that they are often unprepared for. The authors explore the use of pairwise comparison techniques to better inform medical decision making in an application of choosing between three major cochlear implant manufacturers. This paper appears to be the first study to apply a pairwise comparison decision making approach for cochlear implant device selection. Also, unlike many medical decision making studies that are developed by the healthcare professional, this model and analysis was conducted entirely by the patient for the purpose of making the real-world decision of a device. It therefore demonstrates the use of sophisticated decision analysis tools to inform complex patient-based medical decision making. The hierarchical model was built and used for the patient to make a device selection with low values of inconsistency.
\end{abstract}

\section{INTRODUCTION}

Informed decision making is becoming ever more important given the increasing expense of healthcare. Over the last decade, this has resulted in a growth of research in a wide range of domains of medical decision making. A comprehensive survey of decision support systems in patient decision making for treatment and screening [1] found that across a range of studies, "Decision aids do no better than alternative interventions on people's satisfaction with decision making, anxiety, or health outcomes such as quality of life or condition specific quality of life." Having said that, they found that the decision support tools generally helped the patient in several other important ways such as developing realistic expectations for procedure outcomes.

A joint report by the National Academies of Science, Engineering, and Medicine focused on hearing treatment for adults [2]. They state that "In the United States, an estimated 30 million individuals (12.7 percent of Americans ages 12 years or older) have hearing loss in both ears." People with hearing loss in one ear expands this population still further. While their report was focused on hearing aids, many of their comments about the decision making challenges faced by patients apply to other forms of hearing loss treatment.

This research study was motivated by the diagnosis of profound, single-sided deafness for one of the authors. For a variety of reasons, three separate specialists recommended a cochlear implant which then entails selecting a particular product. It quickly became apparent that while there was a lot of information, selecting a product was a hard decision-an issue for which our field of engineering and technology management is well-suited to provide insight.

\section{PRELIMINARIES}

Making decision can become a very challenging task especially when there are multiple criteria to consider that are difficult to measure and prioritize. Pairwise comparison is a method that breaks down the decision making process into simple judgment between two alternatives and also provides a way for the decision maker to measure preferences and come to a conclusion among alternatives [3]. Buying a car is a very common example where there are more than one criterion to consider and each one of them can be as important. Sales price of the car as well as its maintenance costs, gas millage, its engine capacity, its cargo and interior space and durability are common criteria to consider. There is not an easy way to measure the importance of these criteria and prioritize them. Pairwise comparison provides the tools to make the decision making process much simpler and enable the decision maker to make trade-offs. Analytical Hierarchy Process (AHP) developed by Saaty, is a multi-attribute decision making methodology that prioritizes alternatives through pairwise comparison. It allows incorporating tangible and intangible criteria towards making a decision and provides a way to measure their priority. Using AHP, the decision maker breaks down the decision into a hierarchy with the lowest level being the alternatives and the highest level being the goal with criteria and sub-criteria in the levels between the two. The decision maker uses pairwise comparisons to set his or her relative preference between two alternatives or subcriteria with respect to the criterion on the higher level and eventually a final priority for the alternatives are obtained [3]. This paper uses Hierarchical Decision Model (HDM) which is similar to AHP except that HDM uses Constant-Sum calculations instead of Eigenvectors in AHP [4].

AHP has been widely used in different application areas as a decision making methodology. Examples include selection of a multi-media authorizing system, equipment selection for manufacturing system and selection of best management style for improving human performance [5]-[7]. Examples of using HDM as decision modeling tool can be found in [7-9].

In 2008, Liberatore and Nydick [11] did a literature review on the application of AHP in medical and health care decision making. There are few articles on the subject prior to 1988, however, the number of articles increased to 3 per year 
since 1997. The authors reviewed 50 articles and in conclusion found AHP as a promising decision making support tool in decision making between patient and doctor, evaluation and selection of therapists and treatments, and the evaluation of health care technologies and policies. Richman, et al. [12] applied AHP to develop a physician-patient joint decision model for selection of prostate cancer treatment. Liberatore, et al. [13] applied AHP as a decision support tool for African-American men to decide whether they are willing to go under a prostate cancer examination.

Pecchia, et al. [14] used AHP to synthesize the diverse needs for a computed tomography scanner by using medical professionals to compare twelve criteria in four categories listed in Table 1. While the twelve characteristics are quite different for a large CT scanner than for a cochlear implant, the four higher level categories are useful. Pecchia, et al., used five medical professionals, each with over two decades of medical experience. These experts came from five different specialties: radiology, ear surgery, neurology, emergency neurology, and emergency. Coincidentally, one of these experts (representing ear surgery) specialized in pediatric cochlear implants but the context is quite different from that of this study.

TABLE 1: AHP CRITERIA USED BY PECCHIA, ET AL. [14] FOR EVALUATING CT SCANNERS

\begin{tabular}{|c|c|}
\hline High level Categories & Criteria \\
\hline Performance & $\begin{array}{ll}\text { - Spatial resolution } \\
\text { - Speed run } \\
\text { - } \\
\text { Processing software } \\
\end{array}$ \\
\hline Patient Safety & $\begin{array}{ll}\text { - } & \text { Patient radiation dose } \\
\text { - } & \text { Patient monitoring } \\
\text { - } & \text { Contrast medium control } \\
\end{array}$ \\
\hline Usability & $\begin{array}{ll}\text { - } & \text { Application support } \\
\text { - } & \text { User-friendly GUI } \\
\text { - Interoperability }\end{array}$ \\
\hline Technical Issues & $\begin{array}{l}\text { - } \text { On call services } \\
\text { - } \quad \text { Maintenance } \\
\text { - } \quad \text { Data storing }\end{array}$ \\
\hline
\end{tabular}

\section{A. Pair wise comparison method in HDM}

HDM uses the Constant-Sum method to calculate the priorities of elements on each level in the hierarchical decision model with respect to the criteria or goal node in the higher level. Consider four criteria cost, gas mileage, cargo space and engine capacity for purchasing a car. Let's call the criteria a, b, c and d respectively. The first step is to create $\frac{n(n-1)}{2}$ possible pairs for the pairwise comparison and in this case will be 6 pairs $a b, a c, a d, b c, b d$ and $d c$. The decision maker will distribute 100 points between each pair with respect to the goal which is purchasing a car. For example, if cost is twice as important as gas mileage, in comparing $a$ with $b, a$ will be 66 points and $b$ will be 33 . If cost and cargo space are as important, $a$ and $c$ each will get 50 points.

The detailed procedures of hierarchical decision modeling can be found in a variety of sources [8]-[10] but conceptually, it can be thought of as using the decision maker or expert's elicited relative weights obtained through pairwise comparisons to calculate specific weights for each criteria in multiple ways. If the different ways of calculating specific weights give different values of specific weights for a single decision maker, this difference is ascribed to inconsistency. If multiple decision makers are involved and arrive at different specific weights, this is termed disagreement.

\section{COCHLEAR IMPLANT TECHNOLOGY}

Cochlear implants are a sophisticated technology for getting audio signals transmitted directly to auditory nerve cells, bypassing many of the possible causes of hearing loss. Arungiri and Mathew previously studied the development of cochlear implant technology in PICMET [15]. Fundamentally, a cochlear implant consists of five key functional pieces described in Figure 1.

The external processor is the part that is most visible. It usually has two major external pieces. The first, labeled A, is a device that sits behind the ear (BTE) and includes microphone(s), battery(ies), and digital signal processing functions in a form that looks similar to many hearing aids. A short cord connects the external processor to a magnetic disc, B, which transmits both power and the "instructions" for the firing of the electrode. The external magnet, $\mathrm{B}$, is then magnetically coupled to an internal magnet, $C$. It has a similar magnetic disc, some processing electronics, $\mathrm{D}$, and an electrode, E, that is then threaded through the skull and/or ear structures into the cochlea. The cochlea is an organ about the size of a green pea and this is where the electrode's firing is received by the auditory nerve which is perceived as "sound" by the patient. The external component(s) can be upgraded over time but the internal components are intended to last a lifetime.

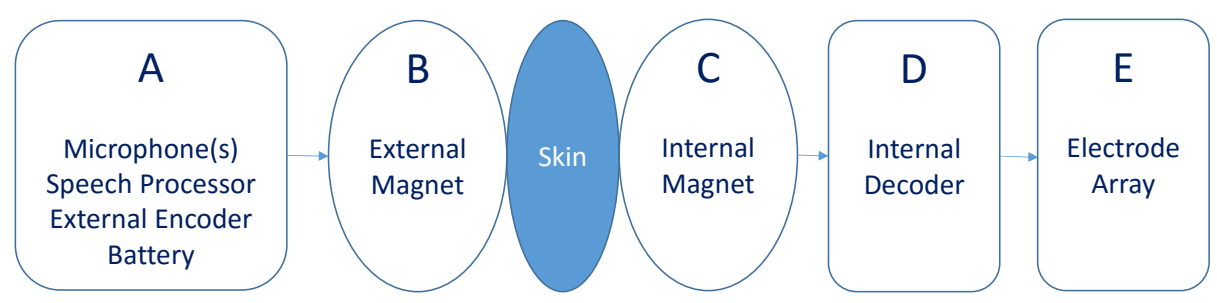

Figure 1. Functional description of the core components of a modern cochlear implant. 
The history of cochlear implant technology has roots that go back to the early days of electrical exploration in the mid eighteenth century when it was discovered that electrical stimulation to the ear could potentially allow some form of hearing [16]. There were some periodic efforts over the years to advance these early results but it took two centuries of progress in both the medical and electronics fields before work could advance to direct electrical stimulation of the auditory nerve in a significant manner. Modern research resulted in significant achievements in the mid $20^{\text {th }}$ century. The 1950s saw stimulation near the auditory nerve and the 1960s had the first implant in the human cochlea and direct stimulation of the auditory nerve [17]. Mudry and Mills [16] provide a rich and accessible history of the development of cochlear implant technology over time.

Currently there are three companies providing cochlear implants in the US: Advanced Bionics, Cochlear Technologies, and Med-El. There are also at least two other manufacturers that are not FDA-approved and therefore unavailable in the US including Zheijiang Nurotron Biotechnology Co. Ltd. in China which began offering cochlear implants in China in 2011. The French company, Neurelec, merged with Oticon Medical and sells the Neuro Cochlear Implant System. For the sake of this paper, we will limit our attention to just the products available in the US.

While the core concept of the product is similar for each of the three manufacturers, there are important differences. The Australia-based company, Cochlear was started in 1981 and is estimated to have a $50 \%$ market share which can be reassuring to some patients when the implanted device will be expected to last a lifetime. Advanced Bionics is the only manufacture to use digital encoding of the signal from the external unit to the internal unit and generally is recognized as having greater future bandwidth potential. Med-El is based in Austria and was founded in 1977. It is the only manufacturer to offer an option to integrate the two external devices (labeled A and B in Figure 1) into a single unit called the Rondo which can be very convenient for some patients such as those that wear eyeglasses. The similarities in physical appearance between the three companies' cochlear implants masks underlying technical approaches. There are major differences in the way that sound is encoded, the compression of the sound for transmitting across the magnetic coupling, and the way that the electrodes are fired. A detailed comparison of these technical differences requires extensive fluency in digital signal processing, psycho acoustics, and audiology. It is therefore beyond the skills of most patients making device selection decisions. The interested reader may review appropriate technical journals.

The patient profile for cochlear implantees varies widely in terms of age range and decision making capability. Some cochlear implants are implanted in elderly patients whose hearing has deteriorated to the point that hearing aids are no longer sufficient. Many future recipients are infants or toddlers that were born deaf and whose normal hearing parents may be unable to bring firsthand knowledge of what it is like to live with deafness. Confounding a difficult decision with the added parental stress of the situation makes rational decision making particularly difficult. Lastly, some recipients are adults that have experienced progressive or sudden hearing loss in one or both ears. Common causes are tumors (acoustic neuromas) and viral infections but often the cause is unknown. The patient (author) of this paper falls in this latter category of a healthy adult with no known cause for the hearing loss.

\section{PILOT APPLICATION OF DECISION MAKING FOR COCHLEAR IMPLANT SELECTION}

\section{A. Challenges of Cochlear Implant Selection}

An author of this paper was recently diagnosed with profound hearing loss in one ear resulting in a specialist (neurotologist) recommendation for a cochlear implant which prompted this study. The specialist said all three manufacturers are able to accommodate the patient's condition and left the final decision of the device to the patient. The patient was handed a stack of company brochures and told to come back the following week to make the device selection including manufacturer, model(s), color(s), and accessories. The patient made an initial device selection but then revisited this decision making analytical decision making methods.

Involving patients in the decision making process is important in healthcare for a variety of reasons. This helps the patient be more informed about realistic expectations and feel greater ownership of the process but also presents a number of special decision making challenges. Choosing a cochlear implant manufacturer is a one-time decision akin to choosing Android vs. Apple iOS, vs. Windows Phone but where the user has never used a cell phone before and will never be able to change platforms despite occasional upgrades. Some additional factors that complicate the decision making include the following.

1. By its very nature, it is almost always the first time someone has made a decision regarding a cochlear implant so there is an unfamiliarity with the relevant decision criteria. Furthermore, for many patients, they may not even have had a hearing aid. Also, the technology is impossible to fully replicate or simulate and trying one out is impossible. This is similar to buying a car without ever having driven a car.

2. The external processor is very visible and easy to relate to compared to the characteristics of the internal device. This may result in over emphasizing matters of appearance. Again, relating it to car buying, if one does not appreciate the engineering of the engine or transmission, it may be difficult to fully judge a car and the car buyer may decide on the number of cup holders or 
the paint color even when major engine and transmission differences exist.

3. The time horizon for different patients (decision makers) is significantly different. It may be a decade for elderly patients but 75 years for an infant. This then affects the priority on future technological capabilities and long-term availability of external devices and support. Having an unsupported cochlear implant would be the equivalent of being stuck with a car that can no longer be refueled.

While decision making for hearing aids is known to be very difficult as shown by both the joint report of the National Academies [2] and at end-user perspective by Consumer Reports [18]. The challenge and impact of cochlear implant decision making is magnified because unlike hearing aids, a patient cannot really test, compare, or change their decision after first usage.

\section{B. Cochlear Implant Device Decision Making Criteria}

The patient considered a variety of factors. A detailed website, Cochlear Implant Help [19] has compiled a comprehensive collection of information on the current cochlear implants made by the three currently US FDA approved manufacturers.

TABLE 2: CRITERIA USED FOR COMPARING COCHLEAR IMPLANTS

\begin{tabular}{|c|c|}
\hline $\begin{array}{l}\text { High level } \\
\text { Categories }\end{array}$ & Criteria \\
\hline Performance & $\begin{array}{l}\text { - Current Implant Technology-How good is the } \\
\text { implant's current capability utilized } \\
\text { Main External Unit - Performance of the system } \\
\text { with the current most popular BTE (external) } \\
\text { device } \\
\text { - Main External Unit's Waterproof- } \\
\text { Waterproofness and dustproofness rating of the } \\
\text { external unit }\end{array}$ \\
\hline Accessories & $\begin{array}{l}\text { - Secondary External Unit - How appealing is the } \\
\text { alternative to the standard BTE unit } \\
\text { - Connection Options - Appeal connectivity } \\
\text { options such as Bluetooth } \\
\text { - Bonuses - Bonus programs from the } \\
\text { manufacturer such as a free upgrade to a next } \\
\text { generation BTE unit }\end{array}$ \\
\hline Future Issues & $\begin{array}{l}\text { - Future Implant Technology - How much } \\
\text { untapped capability is likely to be available in } \\
\text { the internal (implanted) unit? } \\
\text { - Warranty \& Reliability - Warranty and } \\
\text { brand reliability }\end{array}$ \\
\hline
\end{tabular}

The characteristics considered by the patient are divided into three categories: Performance, Accessories, and Future Issues.

\section{1) Performance Characteristics}

Performance into three important capabilities. First is the current performance of the implant. Since this is the unit that the patient must live with permanently, the internal unit is critical. It is a function of many design elements such as the maximum stimulation rate (pulses per second), number of channels, and the maximum number of electrodes that can be simultaneously fired.

The performance of the main external unit can be expected to be upgraded over time but is a function of many design decisions including the number and placement of microphones, power consumption, and sound encoding algorithms.

The external unit is expected to last many years before being replaced but experience with cell phones indicates that water, sweat, dust, and other contaminants are likely to be a problem. While cochlear implants are improving significantly in this area, there is still a long way to go. Fortunately, this is one area where there is a well-defined industry standard, the International Protection Marking or IP Code. The best IP rated cochlear implant is the Naida from Advanced Bionics with an IP57. The first digit indicates solid particle or dust protection and has values ranging from zero to six. The second digit reflects the liquid or more specifically water protection and ranges from zero to nine. The Naida's IP57 then means that it is "dust resistant" and can be immersed to a depth of one meter for up to 30 minutes.

\section{2) Accessory Characteristics}

The secondary external unit reflects the fact that two of the three manufacturers make an alternate unit to the common BTE unit and many clinics have an agreement for patients to get a second external processor. These alternate units provide different features that can be quite helpful beyond simply having a backup in case the primary one breaks. Specifically, Advanced Bionics' Neptune has an IP68 rating making it an excellent option for swimmers. Med-El's Rondo unit integrates the magnetic disc and the BTE piece into a single unit so there is nothing sitting upon the ear. While the Rondo may not provide ideal placement for microphones, it can be very convenient for eyeglass wearers.

Connectivity options vary across manufacturers. This includes accessories for making a Bluetooth connection, wireless microphones, and telecoil which is commonly available in many public spaces such as theatres and churches. While capabilities are improving, the progress is slower than might be expected since regulatory approval by both the FCC and FDA may slow feature availability.

The last accessory related criteria is the included bonuses offered. The manufacturers periodically provide promotional add-ons that can be important. For example, in 2015, Med-El offered patients a free Rondo unit. In a "two-processor" clinic, patients could then receive three external processors. Since an external processor may cost approximately $\$ 6000$, this can be very beneficial. Another common promotion might be an additional wireless accessory or a free upgrade offer to trade in the current processor for a new processor when it is approved and available. 


\section{3) Future Issue Characteristics}

As mentioned earlier, a cochlear implantation is a longterm decision so it is important to consider what the future may hold. The first issue is Future Implant Technology which relates to how much future capability the implant may be able provide to upgraded external units over the years. While there are many detailed engineering elements that go into this, the maximum data rate for transmitting information from the processor to the implant is a very important performance limiter. Advanced Bionics supports $1 \mathrm{Mb} / \mathrm{sec}$., while Med-El is at $0.5 \mathrm{Mb} / \mathrm{sec}$, , and Cochlear is at 0.5 $\mathrm{Mb} / \mathrm{sec}$. For comparison, Audio Compact Discs (CD-DA) typically have a bit rate of $1.411 \mathrm{Mb} / \mathrm{second}$ and many MP3s are encoded at $0.128 \mathrm{Mb} /$ second. Having said that, real-time encoding is complicated and the electrodes also create limitations that are likely to always be far from ideal. While cochlear implant recipients may enjoy music, technical limitations will prevent them from matching the richness of music from a CD or even a heavily compressed MP3. Another characteristic of future performance is the maximum input dynamic range which is $80 \mathrm{~dB}, 75 \mathrm{~dB}$, and $45 \mathrm{~dB}$ for Advanced Bionics, Med-El, and Cochlear respectively.

The Warranty and Reliability criteria is meant to reflect long term reliability and support from the company. Currently, it appears that each of the companies offer a ten year warranty, therefore, warranty won't be a differentiator among the three alternatives. A listing from Cochlear Implant Help shows the number of reported problems to the FDA over time but since this is a count rather than rate, it is affected by sales volume and difficult to interpret. While manufacturers have had past problems, it is hard to interpret this past data to future reliability since the manufacturers have apparently addressed the problems. A third element of this characteristic would be long-term prospects for the company. Current market share or market capitalization for the company or parent company could be used as a proxy to try to predict long-term likelihood of support but these are likely to be poor predictors whether the product will be supported in thirty or forty years.
4) Characteristics Not Included in the Current Model

Just as in the classic example of a car there are many other differences among products that may not be reflected by the criteria of the analysis. Similarly, the cochlear implants vary in many other ways beyond those listed which are not included in the current model. The patient (author) deemed these to be difficult to assess and of lesser importance in his usage case. These could be important for other patients and could be added in a future model. Examples of these other factors may include implant size, compatibility with magnetic resonance imaging (MRI) machines, implant's impact resistance, battery usage or energy efficiency, and ease of use. Notably absent is cost but it appears that each of the three products have similar costs. Given the current structure of the US healthcare system, it is hard to get costs of the products, particularly for out of pocket costs, and the patient is not asked to factor that into the decision. If the decision was at the level of the insurance or health care provider, cost would be important.

\section{Patient Input}

The patient did a basic pair-wise comparison of the eight criteria using the HDM Software, 2.0 beta, http://research1.etm.pdx.edu/hdm2/. The decision hierarchy summarized in Table 3.

Table 3 provides the specific pairwise comparison weights for the eight criteria indicating the weight of the criteria listed in the row compared against the criteria in the column on a 100 point scale with 50 being indifferent between the two criteria. Only the upper triangular portion of the matrix is shown. The lower triangular values are simply 100 minus the upper triangular value. For example, Secondary Exit Unit is given 40 compared to the Current Implant Tech. The lower triangular value would then be 60 . This indicates that that the criteria for Current Implant Tech is $50 \%(60 / 40=1.5)$ more important than the Secondary Ext Unit.

The values in Table 4 describe how the patient perceives each of the three alternatives perform on the eight criteria relative to the others. These values are similar to the weights from Table 3 but now each row corresponds to a small

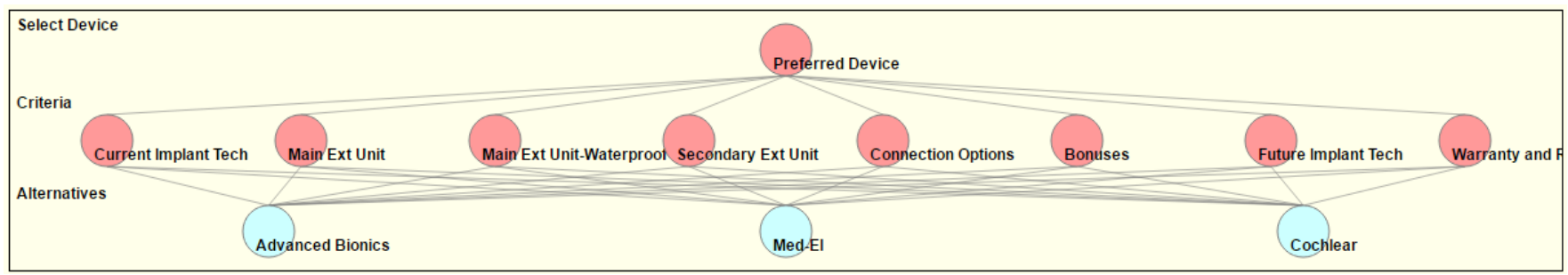

Figure 2: Decision hierarchy used for evaluating cochlear implants. 
TABLE 3: HDM WEIGHTS ASSIGNED FOR THE CRITERIA IN THE ROW VS. THE COLUMN.

\begin{tabular}{|c|c|c|c|c|c|c|c|}
\hline & $\begin{array}{c}\text { Main\% } \\
\text { Ext\% } \\
\text { Unit }\end{array}$ & $\begin{array}{c}\text { Main\%xt\% } \\
\text { Unit* } \\
\text { Waterproof }\end{array}$ & $\begin{array}{c}\text { Secondary\% } \\
\text { Ext\%nit }\end{array}$ & $\begin{array}{c}\text { Connection\% } \\
\text { Options }\end{array}$ & Bonuses & $\begin{array}{c}\text { Future\% } \\
\text { Implant\% } \\
\text { Tech }\end{array}$ & $\begin{array}{c}\text { Warranty\% } \\
\text { and\% } \\
\text { Reliability }\end{array}$ \\
\hline Current\%mplant\%ech & 35 & 40 & 40 & 35 & 35 & 60 & 65 \\
\hline Main\%xt\%nit & & 40 & 25 & 30 & 40 & 48 & 60 \\
\hline Main\%xt\%nit*Waterproof & & & 40 & 65 & 50 & 50 & 70 \\
\hline Secondary\%xt\% nit & & & & 40 & 35 & 65 & 75 \\
\hline Connection\%ptions & & & & & 50 & 60 & 70 \\
\hline Bonuses & & & & & & 60 & 70 \\
\hline Future\%mplant\%ech & & & & & & & 60 \\
\hline Warranty\%nd\%eliability & & & & & & & \\
\hline
\end{tabular}

TABLE 4: PATIENT'S PERCEIVED RELATIVE STRENGTH FOR EACH ALTERNATIVE ON THE EIGHT CRITERIA.

\begin{tabular}{|l|l|c|c|c}
\hline & & $\begin{array}{c}\text { Advanced(Bionics } \\
\text { vs. } \\
\text { Med/El }\end{array}$ & $\begin{array}{c}\text { Advanced(Bionics } \\
\text { vs. } \\
\text { Cochlear }\end{array}$ & $\begin{array}{c}\text { Cochlear } \\
\text { vs. } \\
\text { Med/El }\end{array}$ \\
\hline & & & & \\
A & Current(Implant(Tech & $60: 40$ & $70: 30$ & $60: 40$ \\
\hline B & Main(Ext(Unit & $55: 45$ & $50: 50$ & $55: 45$ \\
\hline C & Main(Ext(Unit/Waterproof & $65: 35$ & $55: 45$ & $45: 55$ \\
\hline D & Secondary(Ext(Unit & $25: 75$ & $55: 45$ & $76: 24$ \\
\hline E & Connection(Options & $55: 45$ & $55: 45$ & $50: 50$ \\
\hline F & Bonuses & $30: 70$ & $50: 50$ & $70: 30$ \\
\hline G & Future(Implant(Tech & $75: 25$ & $82: 18$ & $40: 60$ \\
\hline H & Warranty(and(Reliability & $50: 50$ & $50: 50$ & $50: 50$ \\
\hline
\end{tabular}

triangular matrix comparing the three alternatives. These values are subjective based on significant reading and repeated physical examinations of the products but industry experts, other patients, and the company's own personnel are likely to have different perspectives. Some of these may change over time as new accessories are introduced, features are enabled, and other developments. In particular, Bonuses may be affected by the service provider's agreements with the manufacturer and sales promotions. At the time of this elicitation, Med-El was offering a free Rondo unit (external processor) to every new implantee. Given that a decision must be made and the lack of access to independent experts, the values given are a best estimate.

\section{Pairwise Comparison Results}

HDM's results in Table 5 indicate that the most important characteristic is warranty \& reliability or long-term support. This is not at all surprising given that the device is intended to be permanently implanted. While the three current companies in the US are hard to differentiate on this basis, the next two characteristics have a higher differentiation. The performance of the main external unit and the level of the current implant's technology are tied for being the next most important criteria. The implant's technology potential for future improvement is the fourth most important criteria.

The inconsistency score of 0.02 indicates that the patient's elicited values in Table 3 were highly consistent.
TABLE 5: HDM RESULTS DESCRIBING THE RELATIVE IMPORTANCE OF EACH CRITERIA.

\begin{tabular}{|l|c|c|}
\hline \multicolumn{1}{|c|}{ Level\% } & $\begin{array}{c}\text { Preferred+ } \\
\text { Device }\end{array}$ & Rank \\
\hline Current'Implant'Tech & 0.15 & 2 \\
\hline Main'Ext'Unit & 0.15 & 2 \\
\hline Main'Ext'Unit:Waterproof & 0.10 & 6 \\
\hline Secondary'Ext'Unit & 0.08 & 8 \\
\hline Connection'Options & 0.11 & 5 \\
\hline Bonuses & 0.09 & 7 \\
\hline Future'Implant'Tech & 0.13 & 4 \\
\hline Warranty'and'Reliability & 0.19 & 1 \\
\hline \multicolumn{1}{|c|}{ Inconsistency } & $\mathbf{0 . 0 2}$ & \\
\hline
\end{tabular}

Note that results are given to two decimal places to be consistent with the number of significant digits in the elicited data of tables 3 and 4 .

Next we examine how each of the three products perform relative to these eight criteria by synthesizing the values from Table 4 into a relative performance in Table 6. Advanced Bionics' offering is ranked the highest on five criteria, Med$\mathrm{El}$ is highest on two criteria, and all three are tied on the criteria of Warranty and Reliability. The latter is not surprising given the difficulty of distinguishing among the performance of the companies on the Warranty and Reliability has been discussed earlier. 
2016 Proceedings of PICMET '16: Technology Management for Social Innovation

TABLE 6: HDM RESULTS DESCRIBING THE RELATIVE IMPORTANCE OF EACH CRITERION.
\begin{tabular}{|l|c|c|c|c|c|c|c|c}
\hline & $\begin{array}{c}\text { Current } \\
\text { Implant } \\
\text { Lechel-2 }\end{array}$ & $\begin{array}{c}\text { Main } \\
\text { Ext } \\
\text { Unit }\end{array}$ & $\begin{array}{c}\text { Main Ext } \\
\text { Unit- } \\
\text { Waterproo }\end{array}$ & $\begin{array}{c}\text { Secondary } \\
\text { Ext Unit }\end{array}$ & $\begin{array}{c}\text { Connection } \\
\text { Options }\end{array}$ & $\begin{array}{c}\text { Future } \\
\text { Implant } \\
\text { Tech }\end{array}$ & $\begin{array}{c}\text { Warranty } \\
\text { and } \\
\text { Reliability }\end{array}$ \\
\hline Advanced Bionics & $\mathbf{0 . 4 8}$ & $\mathbf{0 . 3 6}$ & $\mathbf{0 . 4 3}$ & $\mathbf{0 . 5 0}$ & $\mathbf{0 . 3 8}$ & 0.23 & $\mathbf{0 . 6 5}$ & $\mathbf{0 . 3 3}$ \\
\hline Med-El & 0.31 & 0.33 & 0.25 & 0.29 & 0.31 & $\mathbf{0 . 5 4}$ & 0.16 & $\mathbf{0 . 3 3}$ \\
\hline Cochlear & 0.21 & 0.31 & 0.33 & 0.21 & 0.31 & 0.23 & 0.19 & $\mathbf{0 . 3 3}$ \\
\hline Inconsistency & $\mathbf{0 . 0 0}$ & $\mathbf{0 . 0 0}$ & $\mathbf{0 . 0 0}$ & $\mathbf{0 . 1 5}$ & $\mathbf{0 . 0 0}$ & $\mathbf{0 . 0 0}$ & $\mathbf{0 . 0 1}$ & $\mathbf{0 . 0 0}$ \\
\hline
\end{tabular}

These results are then collected together to form an overall ranking given in Table 7. The top scoring product is that of Advanced Bionics.

TABLE 7: HDM RESULTS DESCRIBING THE RELATIVE IMPORTANCE OF EACH CRITERIA.

\begin{tabular}{|l|c|c|}
\hline \multicolumn{1}{|c|}{ Level-1 } & $\begin{array}{c}\text { Preferred } \\
\text { Device }\end{array}$ & Rank \\
\hline Advanced Bionics & 0.42 & 1 \\
\hline Med-El & 0.31 & 2 \\
\hline Cochlear & 0.27 & 3 \\
\hline
\end{tabular}

Given that the patient is an engineer, this would be a reasonable result. Placing a significantly higher importance on the Secondary External Unit and/or Bonuses would be required for Med-El to be the preferred alternative holding everything else constant in this decision model.

The patient's original selection before doing detailed research and HDM had been the Med-El system. Upon reflection, this was due to an under appreciation for the technical characteristics and over valuing the benefits of the Rondo system. After looking all of this information over, the patient contacted the clinic before surgery to change the device and company to Advanced Bionics.

\section{DISCUSSION}

\section{A. Limitations}

The problem of cochlear implant decision making can be considered as just one option among a range of other treatment alternatives. Potential alternatives to a cochlear implant include traditional hearing aids, bone conduction, biotech treatments to "revive" the hair cells in the cochlea. While the author carefully considered each of these options, detailing that decision making process is beyond the scope of this current paper but could be investigated in future work.

Since one of the paper's authors needed to make a cochlear implant device selection, this provided an opportunity to try to frame this decision using tools commonly employed in engineering and technology management. It should be recognized that this is only one person's perspective based on available information. This person is by definition - a non-expert in that he has never used a cochlear implant at the time of making the decision, is not an audiologist, or a doctor specializing in these areas (neurotologist). The criteria selected by the author would likely be modified in the future as the patient's circumstances change and as the technology improves. Perhaps an even greater change would occur based on being more fluent in the underlying technology.

\section{B. Future Work}

This study was an exploratory study to frame this complex decision but future work could follow multiple directions.

1. The characteristics could be refined to improve their definitions and usage as well as possibly adding criteria currently excluded as described in section 0 . This might be done using fuzzy cognitive maps.

2. The assessment of the level of performance of cochlear implant on each characteristic is based on one patient's perspective. The patient has no financial interest or other association with any of the three vendors and has not yet received an implant. Therefore, while this represents an honest and impartial appraisal within the limited time of the decision making process, it could be improved by further consulting with industry experts. This could take the form of a second expert panel consisting of surgical experts, audiologists, and well-informed implanted patients which could then assess the performance of the cochlear implants.

3. Testing a more robust decision making model with a variety of patients/decision makers to ensure that the characteristics reflect the range of concerns and priorities. For example, the model was built by a middle-aged professional with single-sided deafness. Certainly the priorities will vary for a patient of a toddler or an elderly user but there are likely additional concerns the current decision maker did not recognize.

4. Evaluating the benefits of the decision making process on decision satisfaction in line with standards in the medical decision making field.

5. This model presumes that a decision for a cochlear implant has already been made and the issue is now selection of a particular device. An earlier stage decision of whether to get a cochlear implant, an alternate or treatment such as bone conduction or potential future biotech treatments, or even deferring over time to allow technology to progress would be useful for many patients. This would require modeling uncertainty regarding future technology development, time value of benefits received, and the opportunity cost of foregoing options.

6. Apply Abbas' robust consistency analysis for the decision maker [20]. 


\section{Proceedings of PICMET '16: Technology Management for Social Innovation}

7. Categorize the criteria so that experts can weigh in on technical differences between the cochlear implant products.

\section{CONCLUSION}

This research was an exploratory study to examine the framing of the decision for a complex medical device. Pairwise comparison techniques such as AHP and HDM can provide a systematic decision support tool to assist the decision maker incorporating a range of disparate criteria. In this case, the process of applying HDM was helpful for balancing these criteria and making a selection. The process of systematic decision making and reflection resulted in the decision maker (patient) changing the product requested before surgery was done.

\section{REFERENCES}

[1] A. O'Connor, C. Bennett, D. Stacey, M. Barry, N. Col, K. Eden, V. Entwistle, V. Fiset, M. Holmes-Rovner, S. Khangura, H. LlewellynThomas, and D. Rovner, "Decision aids for people facing health treatment or screening decisions (Review)," The Cochrane Collaboration, 3, 2009.

[2] Committee on Accessible and Affordable Hearing Health Care for Adults, Board on Health Sciences Policy, Health and Medicine Division, and National Academies of Sciences, Engineering, and Medicine, Hearing Health Care for Adults: Priorities for Improving Access and Affordability. Washington, D.C.: National Academies Press, 2016.

[3] T. L. Saaty, "Decision making with the analytic hierarchy process," Int. J. Serv. Sci., vol. 1, no. 1, pp. 83-98, 2008.

[4] D. F. Kocaoglu, "A participative approach to program evaluation," IEEE Trans. Eng. Manag., vol. EM-30, no. 3, pp. 112-118, Aug. 1983.

[5] V. S. Lai, B. K. Wong, and W. Cheung, "Group decision making in a multiple criteria environment: A case using the AHP in software selection," Eur. J. Oper. Res., vol. 137, no. 1, pp. 134-144, 2002.

[6] M. Dağdeviren, "Decision making in equipment selection: an integrated approach with AHP and PROMETHEE," J. Intell. Manuf., vol. 19, no. 4, pp. 397-406, Jan. 2008.

[7] E. Albayrak and Y. C. Erensal, "Using analytic hierarchy process (AHP) to improve human performance: An application of multiple criteria decision making problem," J. Intell. Manuf., vol. 15, no. 4, pp. 491-503, Aug. 2004.

[8] D. Hallum and T. U. Daim, "A hierarchical decision model for optimum design alternative selection," Int. J. Decis. Sci. Risk Manag., vol. 1, no. 1-2, pp. 2-22, Jan. 2009.

[9] B. Wang, D. F. Kocaoglu, T. U. Daim, and J. Yang, "A decision model for energy resource selection in China," Energy Policy, vol. 38, no. 11, pp. 7130-7141, Nov. 2010.

[10] M. Amer and T. U. Daim, "Selection of renewable energy technologies for a developing county: A case of Pakistan," Energy Sustain. Dev., vol. 15, no. 4, pp. 420-435, Dec. 2011.

[11] M. J. Liberatore and R. L. Nydick, "The analytic hierarchy process in medical and health care decision making: A literature review," Eur. J. Oper. Res., vol. 189, no. 1, pp. 194-207, Aug. 2008.

[12] M. B. Richman, E. H. Forman, Y. Bayazit, D. B. Einstein, M. I. Resnick, and M. D. Stovsky, "A Novel Computer Based Expert Decision Making Model for Prostate Cancer Disease Management," $J$. Urol., vol. 174, no. 6, pp. 2310-2318, Dec. 2005.

[13] M. J. Liberatore, R. E. Myers, R. L. Nydick, M. Steinberg, E. R. Brown, R. Gay, T. Powell, and R. L. Powell, "Decision counseling for men considering prostate cancer screening," Comput. Oper. Res., vol. 30, no. 10, pp. 1421-1434, Sep. 2003.

[14] L. Pecchia, J. L. Martin, A. Ragozzino, C. Vanzanella, A. Scognamiglio, L. Mirarchi, and S. P. Morgan, "User needs elicitation via analytic hierarchy process (AHP). A case study on a Computed Tomography (CT) scanner," BMC Med. Inform. Decis. Mak, vol. 13, p. $2,2013$.

[15] S. Arunagiri and M. Mathew, "Exploring technology evolution using patent classification: A case of cochlear implant technology patents," in Proceedings of PICMET '14 Conference: Portland International Center for Management of Engineering and Technology; Infrastructure and Service Integration, 2014, pp. 1459-1470.

[16] Mudry A and Mills M, "The early history of the cochlear implant: A retrospective," JAMA Otolaryngol. Neck Surg., vol. 139, no. 5, pp. 446-453, May 2013.

[17] Simmons, F Blair, "Electrical stimulation of the auditory nerve in man," Arch. Otolaryngol., vol. 84, no. 1, pp. 2-54, Jul. 1966.

[18] "Hearing Aid Buying Guide," Consumer Reports. [Online]. Available: http://www.consumerreports.org/cro/hearing-aids/buying-guide.htm. [Accessed: 11-Jul-2016].

[19] H. Samuels, T. Hannon, and T. Lannin, "Cochlear Implant Help," Cochlear Implant Help. [Online]. Available: http://cochlearimplanthelp.com/.

[20] M. Abbas, "Consistency Analysis for Judgment Quantification in Hierarchical Decision Model,” Diss. Theses, Mar. 2016. 